\title{
A memória do risco na alta modernidade: dos pontos de tensão às controvérsias tecnocientíficas*
}

\author{
The memory of the risk in high modernity: from stress \\ points to technoscientific controversies
}

\author{
Alysson Hubner*1 \\ Joel Paese*2
}

\begin{abstract}
Palavras-
chave:

Memória do risco;

Risco;

Pontos de tensão;

Controvérsias

tecnocientíficas;

Modernidade.
\end{abstract}

Keywords:

Risk memory; Risk;

Tension points;

Technoscientific

controversies;

Modernity.
Resumo: O artigo analisa o problema do risco na alta modernidade a partir do conceito de "memória do risco", no contexto da relação entre "pontos de tensão" e "controvérsias tecnocientíficas". Para isso, investiga-se o caso do risco da gripe aviária e da gripe suína. 0 artigo está dividido em duas seções. A primeira trata da "sociedade de risco" e como esse conceito permite articular a ideia de pontos de tensão com o debate sobre controvérsias tecnocientíficas. $\mathrm{Na}$ segunda, analisa-se de que maneira os pontos de tensão e as controvérsias podem ser entendidos pelo conceito de "memória do risco" na alta modernidade. Conclui-se que as diferentes práticas assumidas frente aos dois riscos analisados são explicadas pela influência da "memória do risco".

\begin{abstract}
The article analyzes the problem of the risk in the high modernity through the concept of "risk memory", in the context of the relationship between "tension points" and "technoscientific controversies". To do so, it investigates the case of the risk of avian and swine flu. The article is divided into two sections. The first one deals with the "risk society" and how this concept can articulate the idea of points of tension with the debate on technoscientific controversies. In the second section we analyze how the tension points and technoscientific controversies can be understood by the concept of "risk memory" in high modernity. It is concluded that the different practices undertaken in front of both analyzed risks are explained by the influence of "risk memory".
\end{abstract}

\footnotetext{
* Artigo recebido em 15/02/2014 e aprovado para publicação em 02/05/2014.

${ }^{* 1}$ Professor do Instituto Federal Sul-Rio-Grandense- IFSUL. Doutor em Sociologia - UFPB. E-mail: alyssonhubner@yahoo.com.br.

*2 Professor da Universidade Federal do Mato Grosso (UFMT). Doutor em Sociologia Política pela Universidade Federal de Santa Catarina (UFSC).
} 


\section{Introdução}

O deslocamento da noção de risco pelos sociólogos Ulrich Beck e Anthony Giddens, da periferia para o centro da teoria social contemporânea (GUIVANT, 1998), está relacionada à análise dos fundamentos da sociologia. A partir dos estudos de Beck (1998a, 1998b; 1999) sobre a emergência da "sociedade de risco", nossa análise procura articular a noção de "pontos de tensão", relativa à análise de algumas especificidades do risco, com o debate sobre as controvérsias científicas. Pela noção de "memória do risco", entendida neste artigo como uma derivação da noção de "memória coletiva", serão estabelecidas interfaces entre "pontos de tensão" e "controvérsias científicas". O objetivo é analisar como o retorno de elementos contidos em ambas as situações articula-se em experiências praticadas em momentos cronológicos diferentes, mas que possuem determinadas continuidade e descontinuidade, sejam elas praticadas de maneiras similares, diferentes ou híbridizadas pelos atores sociais envolvidos.

Como exemplo desta dinâmica, situamos as correspondências entre o risco da gripe aviária (ano de 2005) e da gripe suína (ano de 2008). Procuramos demonstrar que a singularidade contida no risco da gripe aviária possuía especificidades que não permitiam correlacionar práticas ulteriores ao seu contexto, pelo fato dos atores sociais não terem ainda constituído uma "memória do risco", por se tratar de algo "novo". Esta situação se inverteu no caso do risco da gripe suína, na medida em que já estava formada uma "memória do risco" nesse outro contexto, o que permitiu aos agentes recorrerem a essa memória para assumir uma prática social dessemelhante de outrora.

O artigo está dividido em duas seções. Na primeira, é possível averiguar a partir de algumas premissas, de que maneira a sociedade passa a ser modificada em virtude da emergência dos riscos. Analisa-se a complexidade do risco a partir dos pontos de tensão e das controvérsias científicas. A segunda parte analisa a noção de "memória coletiva", a fim de explicar a utilidade da noção de "memória do risco" para o entendimento das ações dos atores sociais, frente às situações de risco que são comuns à gripe aviária e à gripe suína, assim como a relação com a segurança ontológica, e como isso se manifesta na relação entre pontos de tensão e as controvérsias científicas.

Na primeira parte foram realizadas pesquisas de campo no que toca aos pontos de tensão (HUBNER, 2014) e as controvérsias tecnocientíficas (PAESE, 2007), a partir da perspectiva da pesquisa qualitativa. Os agentes

Caderno eletrônico de Ciências Sociais, Vitória, v. 2, n. 1, p. 43-61, 2014. 
entrevistados na primeira pesquisa eram os membros do Comitê Estadual de Sanidade Avícola de Santa Catarina ${ }^{1}$, comitê criado a partir da criação do Plano Nacional de Prevenção a Influenza Aviária no ano de 2006, que associou agentes públicos e privados que trabalhavam com a questão avícola no Brasil. Na segunda pesquisa, foram entrevistados protagonistas da controvérsia sobre a autorização para plantio e comercialização de Organismos Geneticamente Modificados no Brasil, durante o processo de aprovação de regulamentação da "lei de biossegurança", a Lei 11.105, de 24 de março de 2005. Entrevistaram-se representantes do Greenpeace, Instituto de Defesa do Consumidor, Associação Nacional de Biossegurança, Federação da Agricultura do Rio Grande do Sul, Ibama e Embrapa.

Na segunda parte, as inferências realizadas a partir da similitude dos problemas (gripe aviária e suína) foram provenientes de uma revisão bibliográfica, observada na estruturação do problema junto aos meios de comunicação, bem como de trabalho de campo realizado. A observação das diferenças no que diz respeito à construção realizada de maneira ativa por parte dos agentes envolvidos no caso da gripe aviária, e de maneira inativa por parte dos agentes envolvidos no caso da gripe suína (praticamente os mesmos), foi realizada a partir da pesquisa bibliográfica. Assim, pudemos explicar por que algo foi tomado enquanto um problema em um contexto, e passou a ser considerado com um não problema em outro contexto.

\section{Sociedade de risco, pontos de tensão e controvérsias}

Segundo Beck (1997), na modernidade podem ser distinguidas duas situações:

(i) Um estágio no qual os efeitos e as autoameaças sistematicamente produzidas pela sociedade industrial são tomadas como "riscos residuais", controláveis a partir das suas instituições.

(ii) Uma situação em que "as instituições da sociedade industrial tornam-se os produtores e legitimadores das ameaças que não conseguem controlar." (p. 15-16).

\footnotetext{
${ }^{1}$ O Comitê Estadual de Sanidade Avícola de Santa Catarina é formado por oito instituições públicas e privadas, as quais são citadas a seguir: Associação Catarinense de Avicultura (ACAV), Companhia Integrada de Desenvolvimento Agrícola de Santa Catarina (CIDASC), Empresa Brasileira de Pesquisa Agropecuária (EMBRAPA), Federação da Agricultura e Pecuária do Estado de Santa Catarina (FAESC), Secretaria da Agricultura e Desenvolvimento Rural de Santa Catarina (SAR), Superintendência Federal de Agricultura em Santa Catarina (SFA/SC), Sindicato das Indústrias de Carnes e Derivados do Estado de Santa Catarina (SINDICARNE), Universidade do Estado de Santa Catarina (UDESC).
} 
O que se observa, portanto, é uma reconfiguração estrutural da modernidade, em que a produção de riqueza está necessariamente associada à produção de riscos. Os conflitos relacionados à distribuição dos benefícios da sociedade industrial são substituídos pelos problemas e conflitos derivados da "produção, definição e distribuição dos riscos produzidos de maneira científico-técnica." (BECK, 1998a, p. 25).

A natureza paradoxal do risco é uma das características centrais da modernidade, segundo Beck (1997). A crise ecológica, por exemplo, bem como as tentativas de expandir e intensificar o controle sobre a natureza, produziram o seu oposto, ou seja, mais incertezas, riscos e descontrole. 0 resultado é o retorno do que era considerado superado pelo Iluminismo, o reino da incerteza e da ambivalência, numa inversão de expectativas pela qual "viver e agir na incerteza torna-se uma espécie de experiência básica." (p. 23).

Ao propor a emergência da "sociedade de risco"2, Ulrich Beck (1997) afirma que a sociedade passa por transformações significativas nas relações sociais em virtude dos riscos que emergiram na atual fase de realização da modernidade. Sua teoria rompe com algumas perspectivas teóricas vigentes nas ciências sociais, dentre elas o entendimento da sociedade exclusivamente a partir da dimensão econômica.

De modo abrangente, risco pode ser definido como o perigo de dano a algo considerado valioso. Mais especificamente, risco é uma autoameaça derivada do sucesso do processo de modernização da sociedade, caracterizado pela incerteza generalizada a respeito de sua previsibilidade e tratamento (BECK, 1998). Giddens (2002), por sua vez, emprega o conceito de "riscos de alta consequência", definidos como riscos que carregam consequências para um grande número de pessoas, as quais não se encontram nas melhores condições para enfrentá-los, pois sua estimativa precisa é praticamente impossível.

De acordo com Beck (1997; 1998a; 1998b, 1999), a sociedade de risco não é a sociedade de classes. Com a centralidade do risco, a dinâmica de desenvolvimento da sociedade passa a ser a segurança, ao contrário da sociedade de classes, em que a dinâmica de desenvolvimento social é a igualdade. Neste caso, a igualdade passa a dar lugar à segurança. Se na sociedade de classes os indivíduos procuram "alcançar o bom", na sociedade de riscos os indivíduos procuram "evitar o pior". A frase definidora da

\footnotetext{
2 De acordo com Beck (1997, p. 15), "este conceito designa uma fase do desenvolvimento da sociedade moderna, em que os riscos sociais, políticos, econômicos e individuais tendem cada vez mais a escapar das instituições para o controle e a proteção da sociedade industrial."
}

Caderno eletrônico de Ciências Sociais, Vitória, v. 2, n. 1, p. 43-61, 2014. 
condição individual na sociedade de classes é: "tenho fome", em que se estabelece a comunidade da miséria. Já na sociedade de riscos a frase impulsora é: "tenho medo", em que estabelece a comunidade do medo.

Observa-se que a distinção de classes é relativizada, diferentemente do que sugere a teoria social clássica. Em um caso extremo como o da bomba atômica, não há distinção entre classes. Os riscos transcendem a situação econômica, pois é difícil conceber tal distinção numa situação em que os indivíduos passam a estar submetidos aos riscos indistintamente. Neste sentido infere-se que o risco é "democrático".

É importante salientar que o risco não está dissociado dos recursos financeiros, pois estes são necessários para seu enfrentamento. A variável econômica é importante, mas não é a principal nesta dinâmica. A informação, por exemplo, pode não estar correlacionada à dimensão econômica, pois para o enfrentamento dos riscos a informação é condição sine qua non da ação prática, mais do que um processo econômico autorreferenciado.

Conforme Beck (1997; 1998a, 1998b), o caso de Chernobyl é o marco da gênese da "sociedade de risco". As consequências dos riscos na sociedade possuem uma natureza multidimensional: cultural, política, científica, social, etc. A noção de antagonismo das classes sociais, própria de uma perspectiva economicista, sugere que os indivíduos possuem interesses excludentes. Todavia, os interesses passam a ser comuns aos membros da sociedade em uma situação de risco iminente, pois estes podem afetar a todos indistintamente, como no caso de Chernobyl, da bomba atômica, furacões, dos vírus da gripe aviária, gripe suína, dentre outros.

Deve-se ressaltar que os riscos não são uniformes, pois possuem especificidades. Abordaremos esse atributo do risco valendo-nos da noção de "pontos de tensão"3, em especial no caso do risco da gripe aviária. A complexidade do risco não se esgota ao afirmarmos que existe vinculação entre diferentes esferas sociais. É crucial entender que o retorno dos riscos ou a criação de novos riscos implica a emergência de pontos de tensão anteriormente ausentes. De acordo com Hubner (2007), com o surgimento do risco podem existir três tipos ideais de tensão: ${ }^{4}$

\footnotetext{
3 Definimos "pontos de tensão" como divergências acerca de um tema que opõe atores sociais em uma arena de controvérsias, em que seus posicionamentos poderão vir a ser complementares.

${ }^{4}$ É preciso deixar claro que não sugerimos que estas tipologias sejam categorias puras. Mas são tipos ideais - no sentido utilizado por Max Weber - que existem, portanto, enquanto categorias hipotéticas, e que servem para visualizar os riscos. Estas categorias foram criadas a partir do material empírico, proporcionando a construção de tais tipologias. Em alguns pontos de tensão podem estar presentes tanto o pré-risco, como o trans-risco, o que
}

Caderno eletrônico de Ciências Sociais, Vitória, v. 2, n. 1, p. 43-61, 2014. 
(i) Os pontos de tensão pré-risco: são aqueles pontos de tensão que existiam anteriormente ao risco, mas que passaram a ser extintos com a sua emergência. Nestes casos podemos visualizá-los quando os conflitos entre as agroindústrias foram extintos. Se em uma situação em que inexistia o risco, as agroindústrias disputavam mercados internacionais entre si, e passaram a ter embates econômicos e políticos em vista dessa disputa por mercados, a emergência do risco da gripe aviária as uniu em virtude de um elemento que Ihes era comum. Neste caso, como descrito anteriormente, corrobora-se a teoria da sociedade de risco em Ulrich Beck.

(ii) Os pontos de tensão pós-riscos: são aqueles pontos de tensão que inexistiam anteriormente ao risco, mas que passaram a existir com o seu surgimento. Este caso foi possível observar entre os produtores comerciais e independentes no Estado de Santa Catarina (Brasil), ou seja, aqueles que produziam comercialmente e aqueles que produziam para a subsistência, sem um comprometimento comercial. Também foi observada essa situação entre os produtores vinculados às agroindústrias (integrados) e os não vinculados (não integrados). Neste caso as medidas foram universais, e deviam ser aplicadas por todos os produtores, independentemente do modo de produção (ou criação). Assim, os produtores (ou criadores) independentes e não integrados, relutaram e resistiram para não aplicar as medidas preventivas.

(iii) Os pontos de tensão trans-risco: são aqueles pontos de tensão que existiam anteriormente ao risco e que continuaram a existir mesmo com o seu surgimento, ou seja, independentemente do risco. Este caso é exemplificado pela tensão existente entre as agroindústrias e os avicultores. Neste caso, o inimigo em comum era a gripe aviária, e os avicultores e as agroindústrias seriam afetados de maneira democrática pelo vírus. Todavia, persistiu uma tensão no que se referia ao pagamento de tais medidas. Nesse sentido, a tensão não desapareceu por completo, e por isso classificou-se na terceira categoria. O que ocorreu foi um deslocamento da tensão.

É preciso analisar o caso citado no ponto de tensão trans-risco de forma ponderada. As tensões existentes entre os avicultores $e$ as agroindústrias, no caso que antecedeu ao risco, referiam-se à busca por maior lucratividade pelas partes. Esta tensão se extinguiu com a emergência da gripe aviária, na medida em que os atores envolvidos procuraram "evitar o pior" - no caso da "sociedade de risco" (BECK, 1997) - pois possuíam um inimigo em comum. Sob este aspecto, é possível inferir que o ponto de

não significa que estes pontos de tensão sejam encontrados exclusivamente dentro de uma determinada categoria, como se fossem encaixados perfeitamente em uma só, mas podem estar justapostos. Assim de acordo com cada tensão é possível encontrar formas híbridas.

Caderno eletrônico de Ciências Sociais, Vitória, v. 2, n. 1, p. 43-61, 2014. 
tensão era pré-risco, pois ele era extinto. Todavia, com o estabelecimento das medidas preventivas criadas na interação entre Estado e agroindústrias, o pagamento de tais medidas recaiu sobre os avicultores, emergindo, portanto, uma tensão que não existia até então.

Nesse sentido é possível observar que a tensão entre agroindústrias e avicultores era de pré-risco sob um aspecto e pós-risco sob outro aspecto, pois aniquilou uma tensão, mas criou outra. Assim, a tensão entre as agroindústrias e os avicultores foi híbrida, pois estava mais próxima da categoria trans-risco, na medida em que ela não desapareceu, mas se deslocou. O deslocamento de uma tensão não significa a sua extinção conforme a característica da tensão pré-risco, mas também não significa o surgimento de uma nova tensão no sentido da tensão pós-risco. A tensão trans-risco permite observar uma tensão existente entre os agentes, que é fechada sob um aspecto, mas que se abre sobre outro.

O deslocamento da tensão seguiu a mesma lógica do retorno das controvérsias (PAESE, 2007)5. A controvérsia ocupa uma posição intermediária entre a discussão ${ }^{6}$ e a disputa7. Dentre suas características, está o fato de que ela pode começar com um problema específico e se expandir rapidamente a outros problemas, revelando divergências profundas entre os oponentes. As divergências envolvem tanto atitudes e preferências opostas, bem como desacordos sobre os métodos vigentes para solucionar os problemas. Os contendentes acumulam argumentos que acreditam robustecer suas posições frente às objeções do adversário. O resultado é uma tendência a não decidir a questão, restando apenas inclinar a "balança da razão" a seu favor. Em vista disso, controvérsias não são solucionadas

\footnotetext{
${ }^{5}$ A controvérsia pertence à "família dos fenômenos discursivos dialógicos polêmicos". Sua existência pressupõe: a relação entre duas pessoas, ao menos, que empregam a linguagem e dirigem-se uma à outra, confrontando opiniões, argumentos, teorias etc., imprevisibilidade e a possibilidade e uso do direito de contestação ao oponente por parte de cada um dos contendentes (DASCAL, 1994). Além de Dascal (1994), o autor analisa o problema da controvérsia em outros artigos. Ver Dascal (1990) e Dascal (1998). Para um comentário crítico ver Bassols (2001). Disponível em: <http://www.filosoficas.unam.mx/ tomasini/home.html>. Acesso em: 10 ago. 2006.

${ }^{6}$ A discussão é uma polêmica em que é possível circunscrever com precisão o objeto, seja ele um tema ou um problema. Sua singularidade está em permitir chegar a soluções pela correção do erro graças à aplicação de procedimentos aceitos no campo, sejam eles provas, cálculos, repetições de experimentos, dentre outros.

7 Da mesma forma que a discussão, a disputa é uma polêmica em que seu objeto consiste em uma divergência bem definida. Diferentemente da discussão, os procedimentos mutuamente aceitos para decidir entre atitudes, sentimentos ou preferências inexistem e, portanto, não têm "soluções". Em geral, as divergências subjacentes a elas tornam-se disputas sobre outros tópicos específicos. Pode ocorrer que alguns oponentes vejam, na posição de seu oponente, os sintomas de uma enfermidade, frente à qual a única atividade apropriada é terapêutica.
} 
nem dissolvidas, mas permanecem em latência. Quando uma nova correlação de forças entre os atores se estabelece, as controvérsias ressurgem no debate público, o que implica seu retorno recorrente.

Na modernidade reflexiva os riscos manufaturados, na forma de transriscos, estão associados às consequências do desenvolvimento da ciência e da tecnologia, o que acarreta controvérsias tecnocientíficas, que situam em campos antagônicos coalizões de leigos, peritos, empresas e ONGs. Nelkin (1995) classifica tais controvérsias em cinco tipos:

(i) A primeira disputa ${ }^{8}$, por sinal a mais intensa e de difícil tratamento, relaciona-se às implicações sociais, morais e religiosas de uma teoria científica ou prática de pesquisa.

(ii) A segunda disputa relaciona-se à tensão entre os valores ambientais e as prioridades políticas e econômicas.

(iii) O terceiro tipo de disputa focaliza os riscos à saúde, associados às práticas industriais e comerciais, resultando em choques entre as empresas e seus interesses econômicos e as pessoas preocupadas com os riscos.

(iv) O quarto tipo de disputas sobre as aplicações tecnológicas reflete a tensão entre expectativas individuais e objetivos sociais ou comunitários.

(v) O quinto tipo de disputas está mais restrito ao âmbito interno da ciência e da técnica. São conflitos relacionados a questões de equidade na distribuição de recursos dentro da própria ciência.

Em contextos de conflitos a respeito de políticas, a expertise técnica se transforma num recurso político crucial, uma vez que o poder e a influência dos atores nas controvérsias dependem, em grande parte, do acesso ao conhecimento e da capacidade de questionar os dados utilizados para legitimar decisões. Em vista disso, todos os lados da disputa procuram alistar os cientistas, pois suas interpretações e predições são julgadas racionais e imunes à manipulação política, devido à convicção de que elas se baseiam em dados obtidos através de procedimentos objetivos. A autoridade da expertise científica estaria baseada, portanto, em sua neutralidade. As indústrias se valem da expertise técnica para apoiar seus projetos tanto quanto os grupos de protestos para contestá-los. Um exemplo são os ambientalistas que dispõem de seus próprios experts para expor os riscos potenciais da atividade industrial.

Quando as decisões devem ser tomadas num contexto de conhecimento limitado, em que dificilmente haverá evidência suficiente para

\footnotetext{
8 Nelkin não estabelece diferenças entre discussão, disputa e controvérsia, como o faz Dascal (1994). Para ser fiel à autora, manteremos o termo disputa para significar controvérsia, mas ressalvando que há diferenças entre esses dois fenômenos discursivos.
}

Caderno eletrônico de Ciências Sociais, Vitória, v. 2, n. 1, p. 43-61, 2014. 
se chegar a uma conclusão definitiva, o poder dos atores pode depender da sua capacidade de manipular o conhecimento e desafiar as evidências apresentadas para apoiar determinadas escolhas. Nesse ambiente de incerteza, as decisões que implementam políticas, embora dependentes de expertise técnica, são tomadas com base em valores.

Como a expertise técnica torna-se um recurso, explorado por todas as partes para justificar alegações morais e políticas em disputa, torna-se difícil distinguir fatos científicos de valores políticos. Os debates entre os cientistas revelam as premissas de valor que selecionam os dados considerados importantes, as alternativas cotejadas e os temas considerados apropriados (NELKIN, 1995, p. 453). ${ }^{9}$

A expertise técnica se torna um recurso explorado por todas as partes para justificar suas visões, criar legitimidade e controlar os termos do debate. Durante o processo, os fatos científicos, usados seletivamente, convergem com os valores políticos, fazendo com que a expertise se torne uma arma a mais num arsenal de armas políticas (NELKIN, 1987).

A autora chama atenção para o fato de que a disposição dos cientistas de emprestar sua expertise para as várias facções em disputas amplamente divulgadas minou as suposições de objetividade da ciência, exatamente aquelas que conferiam aos cientistas o poder de árbitros neutros da verdade. Como resultado, as disputas entre os cientistas tornam-se públicas, cuja consequência é aumentar o ceticismo sobre o papel político dos peritos, bem como gerar uma consciência crescente das dimensões políticas das decisões usualmente definidas como técnicas.

Deve-se destacar a implicação desse processo para a segurança "ontológica dos indivíduos". Há uma relação problemática entre confiança e sistemas peritos na modernidade, com implicações no processo de tomada de decisão. Por um lado, a ausência de especialistas pode bloquear a continuidade da vida social, em sua dimensão individual e coletiva, dada a intransparência dos dispositivos tecnológicos. A participação ativa dos peritos em controvérsias tecnocientíficas pode, do mesmo modo, dado o desacordo entre eles, produzir bloqueios, como no processo decisório sobre a regulamentação da área de saúde e de meio ambiente. A questão que se apresenta é: de que modo os indivíduos se posicionam frente às

\footnotetext{
9 No original: "As technical expertise becomes a resource, exploited by all parties to justify competing moral and political claims, it becomes difficult to distinguish scientific facts from political values. Debates among scientists reveal the value premises that shape the data considered important, the alternatives weighed, and the issues regarded as appropriate."
} 
discordâncias entre peritos quanto aos riscos dos novos dispositivos tecnológicos? Como isso afeta a "segurança ontológica" dos indivíduos? (PAESE, 2009).

De acordo com Nelkin (1995), a resolução de conflitos, como aqueles associados aos trans-riscos ${ }^{10}$, reflete, necessariamente, o poder político dos interesses em disputa. Em alguns casos os interesses das indústrias prevalecem. Em outras situações, a persistência dos grupos de protesto tem-se ampliado consideravelmente, o que Ihes permite ampliar o leque de aliados e ter sucesso em algumas situações, como é o caso dos grupos que pressionam a fim de que o governo destine verbas para a pesquisa e 0 estabelecimento de políticas em determinadas áreas.

Situação que também pode ser observada na adoção das políticas adotadas cujo escopo foi a gripe aviária, pois a criação do Plano Nacional de Prevenção a Influenza Aviária (2006) por parte do governo federal, o qual estabelece uma série de medidas preventivas, que passaram a ser incorporadas às práticas sociais, como aquelas adotadas pelos avicultores. Estas medidas por sua vez foram oriundas de um processo político, econômico e social que emergiu a partir da organização no âmbito das agroindústrias (HUBNER, 2007) e que envolveu diferentes atores, como cientistas, empresários, produtores e organizações de consumidores.

As controvérsias tecnocientíficas relacionadas aos pontos de tensão na alta modernidade estão associadas a um tema tratado por Bauman (1999), o problema da "ambivalência". Segundo ele, a ambivalência, característica da atual etapa de realização da modernidade, sugere a necessidade de repensar a ideia de "ordem" presente na ciência positiva, que opera a partir de uma concepção linear. Segundo Bauman (1999, p.12), "dentre a multiplicidade de tarefas impossíveis que a modernidade se atribui e que fizeram dela o que é, sobressai a da ordem (mais precisamente e de forma mais importante a da ordem como tarefa) como a menos possível das impossíveis".

Essa artificialidade da ordem passa a conceder lugar à fragmentação, ao princípio da contingência, bem como à determinação do ambíguo a fim de dissolvê-lo. Não é algo que possa ser suprimido, mas a ambivalência é própria da dinâmica científica, bem como da sociedade. De acordo com o autor (1999, p. 60), "um bocado de ambivalência semiótica e axiológica emerge para se tornar uma característica permanente da existência social, em vez de uma transitória falha dela ainda não consertada" (BAUMAN, 1999,

10 O caso da tensão entre as agroindústrias e os avicultores no Brasil.

Caderno eletrônico de Ciências Sociais, Vitória, v. 2, n. 1, p. 43-61, 2014. 
p.60). Tal princípio que admite a ambivalência está próximo de uma ciência reflexiva.

A ciência reflexiva está inserida na conjuntura dos riscos, sendo atribuído a ela um caráter de definição, geração e preconização dos mesmos, pois "a ciência converteu-se em (com) causa, instrumento de definição e fonte de solução de riscos, de modo que assim se abrem novos mercados para cientificação. $O$ desenvolvimento cientifico-técnico se torna contraditório em vista do intercâmbio de riscos, por ele mesmo coproduzidos e codefinidos, e de sua crítica pública e social." (BECK, 1998, p. 203). ${ }^{11}$

A partir da definição do risco da gripe aviária, e com ela das medidas e das ações práticas adotadas, foi possível observar algumas similitudes com relação à gripe suína. Nessa interface dos riscos, cabe salientar o modo como a experiência do risco da gripe aviária gerou determinados posicionamentos dos atores sociais frente à gripe suína no contexto global. O objetivo da próxima seção é explicar como isso pode ser entendido através da noção de "memória do risco".

\section{"Memória coletiva" e "memória do risco"}

A noção de "memória do risco" está relacionada ao conceito de "memória coletiva" de Halbwachs (2006), o que exige, portanto, explicar de início em que consiste a "memória coletiva". Segundo Halbwachs (2006), as lembranças estão relacionadas a um processo social, no qual os indivíduos necessitam vincular-se ao contexto social no qual estão inseridos, para que sejam suscetíveis de lembrarem acerca de um determinado fato, passando assim a possuir uma determinada reflexão e percepção. As formulações das percepções passam a estar constituídas por uma determinada memória coletiva, em que os sujeitos remetem para os grupos em que estão incorporados.

Assim, "só lembramos se nos colocamos no ponto de vista de um ou mais grupos e se nos situarmos em uma ou muitas correntes de pensamento coletivo" (HALBWACHS, 2006, p. 41). De acordo com essas premissas, grande parte daquilo que lembramos os outros nos fazem recordar, o grupo fornece elementos para que os indivíduos lembrem. Segundo Halbwachs (2006, p. 41),

\footnotetext{
11 "La ciencia se ha convertido em (com) causa, instrumento de definición y fuente de solución de riesgos de modo que así se abren nuevos mercados para la cientificación. El desarrollo científico-técnico se hace contraditório por el intercambio de riesgos, por él mismo coproducilos y codefinidos, y su crítica pública y social."
}

Caderno eletrônico de Ciências Sociais, Vitória, v. 2, n. 1, p. 43-61, 2014. 
não basta reconstruir pedaço a pedaço a imagem de um acontecimento do passado para obter uma lembrança. É preciso que esta reconstrução funcione a partir de dados ou de noções comuns que estejam em nosso espírito e também no dos outros, porque elas estão sempre passando destes para aqueles e vice-versa, o que será possível somente se tiverem feito parte de uma mesma sociedade, de um mesmo grupo. Somente assim podemos compreender que uma lembrança seja ao mesmo tempo reconhecida e reconstruída.

A dificuldade da lembrança está correlacionada à não vinculação dos contextos sociais, trazendo obstáculos nesse processo de recordação quando os indivíduos não estão inseridos no grupo. Entretanto, o grupo cuja referência passa a estar vinculada à memória, não se refere à sua totalidade, mas a uma parte, a uma fração do grupo (HALBWACHS, 2006). Verifica-se concomitantemente que para voltar a pensar em algo é necessário que as circunstâncias sejam similares, em que se percorram sequências análogas. Nestas, estão presentes as forças que as circunstâncias reproduzem naquele mesmo instante.

Ao atravessar os diversos ambientes sociais, os pensamentos, objetivados em um fato, uma ideia e em uma sensação tiveram e mantiveram determinadas representações nessas mesmas situações. A disciplina social constitui um importante fator nesse processo da percepção: "na realidade, a percepção resulta de uma demorada operação e treinamento e de uma disciplina (social) que não se interrompe" (HALBWACHS, 2006, p.62). São as representações trazidas de um ambiente para o outro que possibilitam a formulação da memória coletiva, de forma que as condições sociais formulem um determinado conteúdo da memória, e até mesmo reproduzam o mesmo ordenamento existente nos diferentes ambientes sociais.

A memória coletiva é um processo que considera aspectos relativos às estruturas sociais e às interações sociais (SANTOS, 2003), a fim de estabelecer uma relação entre uma perspectiva objetiva e uma subjetiva. Diante da necessidade de decidir em vista de alternativas presentes e futuras, os indivíduos são remetidos ao passado (KEYNES, 1982), a fim de entender $\mathrm{o}$ presente e ter previsibilidade sobre o futuro. As estruturas sociais são fundamentais para as lembranças, passando a recordar a partir de memórias que não são somente suas. Nesta perspectiva, a lembrança passa a ser uma construção social realizada no presente pelos sujeitos, constituída através de um padrão adquirido socialmente, em que a memória coletiva está inserida em um determinado sistema de signos, que por sua vez estão fixados no tempo e no espaço.

Caderno eletrônico de Ciências Sociais, Vitória, v. 2, n. 1, p. 43-61, 2014. 
Procuramos entender a partir dessa noção de memória coletiva, de que maneira o risco da gripe aviária está e esteve articulado ao risco da gripe suína, em específico no que se refere à tentativa de mudança de nome do último risco. Embora existam muitas interfaces de medidas similares, é possível entender de que maneira a experiência do primeiro risco possibilitou esta diferença no que tange ao segundo risco. Esta prática adotada com relação à gripe suína foi a tentativa de mudança do nome do vírus para gripe $A$. Por que esta tentativa?

Conforme Maganin (2008), é possível estabelecer uma correlação entre a ocorrência de reportagens sobre gripe aviária no jornal americano "The New York Times" e a queda do volume da exportação brasileira de carne de frango em 2006. A possibilidade de que esta situação se repita no caso da gripe suína, no que se refere à diminuição do consumo de carne de porco, pode ser reforçada, uma vez que durante um período, principalmente inicial da gripe aviária, ocorreram significativas diminuições na exportação de carne de frango por parte do Brasil (HUBNER, 2007).

Conforme os entrevistados, o fato de haver um superdimensionamento dado por parte dos meios de comunicação foi um aspecto relevante para compreender porque o risco da gripe aviária se tornou um problema. $\mathrm{Na}$ percepção de um interlocutor:

\begin{abstract}
Eu acho que as informações do jeito que elas foram colocadas na mídia, foram um pouco exageradas. A gente tinha na época reportagens, se a gente for resgatar, de grandes revistas de alcance ao público mais leigo que exageravam.

... se criou um pânico nas pessoas, folclórico no sentido de exagerar para vender. A verdade foi essa, que nós, muita coisa que tivemos que responder foi para combater notícias exageradas da mídia tradicional (EMBRAPA/SC).
\end{abstract}

A abordagem dada à gripe aviária pela mídia foi um elemento de incômodo para os entrevistados, na medida em que afetou de diferentes maneiras a compreensão do fenômeno. Para os atores que produzem conhecimento, o "exagero" (sensacionalismo) foi a estratégia para poder chamar a atenção e poder vender a notícia. Tal sensacionalismo levou ao reforço de instituições associativas e à pressão sobre o governo federal, mas também de criação de estratégias de enfrentamento da ameaça, incluindo o diálogo com a mídia. Esta questão pôde ser verificada na reportagem intitulada "A Imprensa e a Influenza Aviária", ${ }^{12}$ vinculada em uma revista

12 Revista Avicultura Industrial, n. 4, ed. 1144, ano 97, p. 77-77, 2006. 
especializada sobre aves. Esta matéria tratou exatamente do diálogo que o setor avícola passou a estabelecer com os meios de comunicação, através de reuniões realizadas, para que se desse outro tratamento da influenza aviária, mostrando as implicações que esse tratamento midiático daria para o setor avícola.

Como uma de suas possíveis consequências, a terminologia da gripe suína poderia implicar na diminuição do consumo de carne da mesma, gerando um efeito negativo para os setores envolvidos na exportação, de maneira similar ao que ocorreu com o mesmo setor no caso da gripe aviária. Neste sentido, as agroindústrias brasileiras constituíram um grupo de pressão política e econômica para a alteração da terminologia, uma vez que estavam (e estão) diretamente envolvidos nesta questão.

É importante ressaltar que, no caso da gripe aviária, não ocorreu nenhuma tentativa bem sucedida de alteração do nome desse risco para outra classificação. Por que isso não ocorreu? A hipótese é que a memória coletiva neste caso praticamente inexistia nos atores sociais envolvidos, uma vez que se estava diante de algo novo, com riscos novos e de conhecimento restrito. Neste sentido, não havia ainda sido formada uma memória coletiva que permitisse aos atores agir no sentido de alterar o nome do risco da gripe aviária para outro, pois não se sabia necessariamente quais as consequências efetivas de tal risco para o setor.

O período em que a gripe aviária foi discutida, nos meios de comunicação em especial, possibilitou aos atores sociais formarem uma "memória do risco". Um dos aspectos contidos nessa memória consistia na correlação das notícias vinculadas nos meios de comunicação e a diminuição do consumo de carne. Assim, a "memória do risco", inexistente no caso da gripe aviária, já estava presente na situação da gripe suína. A noção de "memória do risco" possibilita entender de que maneira os atores sociais passam a adotar práticas sociais contínuas ou descontínuas frente a situações similares. Com isso, pode-se definir que "memória do risco" é uma memória coletiva de situações de risco que estrutura as ações dos atores sociais na seleção de cursos de ação em vista de riscos presentes ou futuros, baseada na experiência adquirida.

O consumo possui uma relativa autonomia neste processo, estando atrelado a estas convenções sociais que associam o risco do desconhecido a determinados objetos. Estas tentativas de mudanças do nome do risco referem-se à própria tentativa da procura de um relativo controle das práticas de consumo, por parte da iniciativa privada, tendo como canal intermediário - mas com o qual possui uma relação direta - o setor público.

Caderno eletrônico de Ciências Sociais, Vitória, v. 2, n. 1, p. 43-61, 2014. 
O conceito de segurança ontológica possibilita explicar a diminuição do consumo no contexto da gripe aviária, em função da "memória do risco". A segurança ontológica é um dispositivo de confiança básica que os agentes adquirem, funcionando como um casulo protetor que é obtido pela disciplina da rotina (GIDDENS, 2002). As rotinas previsíveis fornecem um sentimento de confiança básica aos agentes. Segundo Giddens (2003, p. 58), "a segurança ontológica é protegida por tais dispositivos, mas mantida de modo mais fundamental pela própria previsibilidade da rotina, algo que é radicalmente perturbado em situações críticas."

A situação crítica a que se remete neste caso é a emergência da gripe aviária amplamente divulgada nos meios de comunicação, que por sua vez implicou em questões desconhecidas pelos agentes, manifestadas no abalo da segurança ontológica, o que pôde ser verificado através da diminuição das exportações de carne de frango em vista da diminuição do consumo de carne (HUBNER, 2007). Tal abalo na segurança ontológica foi momentâneo, na medida em que as exportações e o consumo voltaram aos patamares pré-crise.

É importante destacar que este abalo momentâneo da segurança ontológica pode ser explicado pela não constituição da "memória do risco". Nesse sentido, os agentes passaram a formular questões que não faziam anteriormente, em vista do desconhecido. Todavia, a confrontação de práticas sociais cotidianas contrapostas às informações vinculadas nos meios de comunicação, permitiu a volta da rotina, e como citado anteriormente, a volta da segurança ontológica (HUBNER, 2014). No caso da gripe suína, o fato de já haver sido constituída uma "memória do risco" não implicou na diminuição do consumo de carne de porco, uma vez que os agentes já haviam passado por situações análogas, embora tenha havido uma mobilização por parte dos atores sociais envolvidos para alteração da denominação da doença.

Cabe ressaltar que a classificação e a seleção dos elementos constitutivos da memória procuram não necessariamente incluir, mas excluir. Esta noção é incorporada a partir da junção entre memória coletiva e sistema de classificação. De acordo com Santos (2003, p. 52), "se associamos o conceito de memória coletiva ao de sistema de classificação chegamos à conclusão que a memória é responsável não pela liberdade, mas por processos de exclusão". Estas inferências estão baseadas nos trabalhos de Mary Douglas, que demonstra como as ideias de poluição e pureza demarcam fronteiras simbólicas. Neste sentido, a própria alteração da noção de gripe suína para gripe $A$, implica na exclusão da primeira, a qual possui uma dimensão simbólica em que a primeira é possível de ser

Caderno eletrônico de Ciências Sociais, Vitória, v. 2, n. 1, p. 43-61, 2014. 
correlacionada pelo público leigo, no caso a associação do risco ao suíno, enquanto a segunda passa a ser desconhecida: "o que seria a gripe A?".

As noções de contingência, reflexividade e risco assumem, nesse contexto, uma perspectiva que correlaciona passado e presente: "a premissa de Beck e Giddens de que indivíduos estariam interagindo entre si segundo uma reflexividade nova, aberta ao risco e a novas constelações sociais parte do pressuposto de que o passado que existe é aquele que surge através das narrativas do presente" (SANTOS, 2003, p. 80).

$\mathrm{Na}$ alta modernidade, descrita por Ulrich Beck como "modernização reflexiva"13 (BECK; GIDDENS; LASH, 1997), estão embutidos riscos que estruturam a sociedade. Como foi indicado, as peculiaridades e especificidades de alguns riscos permitiram sua classificação em um ponto de tensão trans-risco (HUBNER, 2007), bem como nos campos em que se desenvolvem as controvérsias tecnocientíficas (PAESE, 2007). Assim, a tensão trans-risco e as controvérsias podem ser compreendidas a partir da "memória do risco", enquanto manifestação da "memória coletiva".

$O$ retorno das controvérsias que envolvem diferentes grupos e setores da sociedade somente é possível a partir de uma determinada prática social, que por sua vez está relacionada ao modo pelo qual foram praticadas anteriormente pelos atores sociais envolvidos, os quais possuem acesso a partir de uma determinada memória. A situação se repete na forma transrisco, na qual o deslocamento da tensão de uma perspectiva para a outra somente é possível de ser inferida a partir da memória coletiva contida na primeira forma de tensão, tornando suscetível aos atores sociais adquirir práticas similares, diferentes ou híbridas, frente a um novo risco. Assim, os retornos das controvérsias e os pontos de tensão estão vinculados a unidades de referência coletiva, especialmente na alta modernidade, possibilitadas através da "memória do risco", que referencia as ações dos atores no presente.

A unidade de referência coletiva que possibilita aos agentes lembrarem-se do risco da gripe aviária não está relacionada a agentes isolados, tão pouco à sociedade como um todo, mas a determinados grupos. Estes grupos estão constituídos por sistemas peritos, não raro envolvidos em controvérsias, bem como por setores político-econômicos definidos na sociedade.

O passado acaba sendo continuamente reconstruído no presente. Neste sentido, a experiência coletiva do risco da gripe aviária permitiu que

13 "O discurso sobre a 'Segunda Modernidade' ou 'modernização reflexiva' visa, antes de tudo, a uma autocrítica radical da teoria e da sociologia ocidentais da modernização" (BECK, 1998 , p. 23).

Caderno eletrônico de Ciências Sociais, Vitória, v. 2, n. 1, p. 43-61, 2014. 
os grupos sociais incorporassem, à nova configuração do risco da gripe suína, uma nova prática social, que pode ser observada na tentativa de mudança de sua classificação. Assim, a "memória do risco" indica, ao mesmo tempo, a manutenção de estruturas sociais fixadas de um risco para outro, e a possibilidade de alteração do curso de ação dos atores sociais.

\section{Conclusão}

A partir da emergência da sociedade de risco em Beck (1997; 1998a; 1998b; 1999), foi possível observar de que maneira as estruturas sociais passam a se modificar com a emergência dos riscos. Todavia, devido às especificidades de alguns riscos, a constatação de um deslocamento de tensões, como no caso do ponto de tensão trans-risco, permitiu estabelecer estruturas sociais mais complexas nesta dinâmica, assim como as controvérsias tecnocientíficas na qual estão envolvidos grupos heterogêneos.

$\mathrm{Na}$ alta modernidade (GIDDENS, 1991), a "destradicionalização" possibilita que a unidade de referência dos agentes passe a não estar mais relacionada à tradição, mas aos sistemas peritos. Nesse contexto, a problemática dos sistemas peritos, dada sua associação à geração de confiança e segurança, em situações de controvérsia entre os "experts", diz respeito, diretamente, ao problema da memória do risco. O enfrentamento do risco, em função de sua memória, decorre, em grande medida, em especial na atual etapa de realização da modernidade, do modo pelo qual os sistemas peritos contribuíram para gerar maior ou menor segurança ontológica. Decorre desse fato a relevância das controvérsias tecnocientíficas na estruturação da memória do risco.

Os pontos de tensão e as controvérsias tecnocientíficas puderam ser combinados pela noção de "memória do risco", no contexto da "memória coletiva". A memória está condicionada por estruturas sociais constituídas por experiências adquiridas em cronologias separadas, mas envolvidas nas situações que se repetem.

A noção de "memória do risco" possibilita entender porque são adotadas práticas dessemelhantes frente a riscos similares. Desta maneira, é possível afirmar que, no caso hipotético da não existência da memória do risco da gripe aviária, ou seja, a experiência adquirida a partir da dinâmica deste risco, dificilmente seriam tomadas ações para alteração do nome de gripe suína para gripe A. Neste sentido, também é possível observar que o processo de classificação e seleção da memória do risco opera a partir de uma lógica simbólica que possibilita excluir uma determinada categoria, mas 
que só foi possível a partir de estruturas sociais definidas a partir da sociedade globalizada.

\section{Referências}

ABEF. Associação Brasileira dos Produtores e Exportadores de Frango, 2006.

Disponível em: <http://www.abef.com.br/Estatisticas/MercadoExterno/Atual.asp $>$. Acesso em: setembro de 2007.

BASSOLS, A. T. La teoría de las controversias de Marcelo Dascal. Disponível em: <http://www.filosoficas.unam.mx/ tomasini/home.html>. Acesso em: 10 ago. 2006.

BAUMAN, Zygmunt. Modernidade e Ambivalência. Jorge Zahar: Rio de Janeiro, 1999.

BECK, Ulrich. La Sociedad del Riesgo: Hacia una nueva modernidad. Piadós: Barcelona, 1998a.

BECK, Ulrich. Liberdade ou Capitalismo. Unesp: São Paulo, 1998b.

BECK, Ulrich. O que é Globalização? Equívocos do Globalismo. Respostas à Globalização. Paz e Terra: São Paulo, 1999.

BECK, Ulrich. GIDDENS, Anthony. LASH, Scott. Modernização Reflexiva. Unesp: São Paulo, 1997.

DASCAL, M. The study of controversies and the theory and history of science. Science in Context, v. 11, p. 147-154, 1998.

. Epistemologia, controvérsia e pragmática. Revista da SBHC, São Paulo, n. 12, p. 73-98, 1994.

DIEESE. Departamento Intersindical de Estatística e Estudos Sócio Econômicos. O preço o frango e a Gripe Aviária. Nota à Imprensa. São Paulo, 09 de Maio e 2006. Acesso em: setembro de 2007. Disponível em: <http://www.dieese.org.br/rel/icv/icvAbril2006GripeAviaria.pdf>.

DOUGLAS, Mary. La aceptabilidad del riego según las ciencias sociales. Piados: Barcelona, 1996.

HALBWACHS, Maurice. A Memória Coletiva. Centauro: São Paulo,2006.

HUBNER, Alysson. Rede Socitécnica da Influenza Aviária: o caso do Brasil. João Pessoa, 2014. 174 f. Tese (Doutorado) - Universidade Federal da Paraíba. Centro de Ciências Humanas, Letras e Artes. Programa de PósGraduação em Sociologia.

HUBNER, Alysson. Risco global da gripe aviária: uma análise sociológica das medidas preventivas em Santa Catarina (Brasil). Florianópolis, 2007. 136 f. Dissertação (Mestrado) - Universidade Federal de Santa Catarina, 
Centro de Filosofia e Ciências Humanas. Programa de Pós-Graduação em Sociologia Política, 2007.

GIDDENS, Anthony. A Constituição da Sociedade. Martins Fontes: São Paulo, 2003.

GIDDENS, Anthony. As Consequências da Modernidade. Unesp: São Paulo, 1991.

GIDDENS, Anthony. Modernidade e Identidade. Jorge Zahar: Rio de Janeiro, 2002.

GUIVANT, J. S. Trajetórias das Análises de Risco: da Periferia Ao Centro da Teoria Social (Risk analysis' trajectories: from periphery to the center of social theory). BIB - Revista Brasileira de Informação Biobliográfica em Ciências Sociais. Rio de Janeiro: UFSC, v.46, n.2, p.3 - 38, 1998.

GUIVANT, Júlia. Sustentabilidade e Métodos Participativos: Os Riscos dos Pressupostos Realistas. Estudos Sociedade e Agricultura, n.19, Outubro 2002: 72-88.

HUTTON, Will e GIDDENS, Anthony. No Limite da Racionalidade. Convivendo com o capitalismo global. Uma conversa (13-80). Record: Rio de Janeiro, 2004.

KEYNES, John Maynard. Teoria geral do emprego, do juro e da moeda. São Paulo: Atlas, 1982.

MOL, A, e SPARGAREN, Gert. Para uma sociologia dos fluxos ambientais. Uma nova agenda para a sociologia ambiental do século 21. Revista Política e Sociedade. 2005.

NELKIN, D. Science controversies: the dinamics of public disputes in the United States. In: Sheila Jasanoff, Gerald E. Markle, et al. (Ed.). Handbook of science and technology studies. Thousand Oaks/London/New Delhi: Sage, 1995.

. The controversies and the authority of science. In ENGELHARDT Jr., H. T.; CAPLAN, A. L. (Ed.) Scientific controversies: case studies in the resolution and closure of disputes in science and technology. Cambridge University Press, 1987.

PAESE, Joel. Controvérsias na tecnociência: o caso da lei de biossegurança no Brasil. Florianópolis, SC, 2007. 298 f. Tese (Doutorado) Universidade Federal de Santa Catarina, Centro de Filosofia e Ciências Humanas. Programa de Pós-Graduação em Sociologia Política.

QUIVY, R. e CAMPENHOUDT, L.V. Manual de Investigação em Ciências Sociais. Lisboa, Gradativa. 1998.

SANTOS, Myrian Sepúlveda dos. Memória coletiva e teoria social. Annablume: São Paulo, 2003.

WEBER, Max. Metodologia das Ciências Sociais. Cortez: São Paulo, 2001. 